\title{
The laparoscopically harvested omental flap and transverse plate fixation for sternal reconstruction in complicated sternal wound infection after cardiac surgery
}

\author{
JM De Raet ${ }^{1 *}$, PT Sergeant ${ }^{2}$ \\ From 23rd World Congress of the World Society of Cardio-Thoracic Surgeons \\ Split, Croatia. 12-15 September 2013
}

\section{Background}

Complicated sternal wound infection after cardiac surgery has an incidence of $0.4-6.9 \%$ and mortality of $7-80 \%$. The ideal reconstructive procedure is still a matter of debate.

\begin{abstract}
Aim
To report our experience with the laparoscopically harvested omental flap and transverse plate fixation for sternal reconstruction after complicated sternal wound infection.
\end{abstract}

\section{Methods}

Between 2010 and 2011, 6 patients with type IV deep sternal wound infection underwent a sternal reconstruction with a laparoscopically harvested omental flap and transverse plate fixation. The median age of the cohort ( 1 female and 5 males), was 72.5 years (range: 4978 years). In 5 patients, a bilateral internal thoracic artery had been used. Considerable preoperative risk factors were present: Obesity with Body Mass Index (BMI) $\geq 33$ (range: 33 - 35: 3 patients); chronic obstructive pulmonary disease (COPD) without steroid therapy preoperatively (4 patients); Diabetes mellitus (type 1: 2 patients; type 2: 1 patient). Abdominal surgery had previously been performed in 4 patients. In 5 cases, the mediastinal wound was prepared with negative pressure wound therapy following surgical debridement. An internal fixation of the sternum was made by titanium locking plates with

\footnotetext{
* Correspondence: janderaet@hotmail.com

'Department of Cardiac Surgery, Heart Center Leipzig, University of Leipzig, Leipzig, Germany

Full list of author information is available at the end of the article
}

sternal and rib-to-rib fixation. The postoperative course of these patients was followed by clinical follow-up.

\section{Results}

Early postoperative sternal stability was seen in all 6 patients. The 30-day perioperative mortality rate was zero, with an overall survival of $100 \%$ until today. Postoperatively no superficial or deep surgical site infections (SSI) were appreciated. Follow-up ranged from 24 to 41 months (median: 28 months).

\section{Conclusions}

Combination of a laparoscopically harvested omental flap and transverse plate fixation can contribute to a successful outcome following complicated sternal wound Infection and deserves serious consideration, regardless of the co-morbidity or previous abdominal surgery.

\section{Authors' details}

'Department of Cardiac Surgery, Heart Center Leipzig, University of Leipzig, Leipzig, Germany. ${ }^{2}$ Department of Cardiac Surgery, University Hospitals

Leuven, Leuven, Belgium.

Published: 11 September 2013

\section{doi:10.1186/1749-8090-8-S1-P58}

Cite this article as: De Raet and Sergeant: The laparoscopically

harvested omental flap and transverse plate fixation for sternal reconstruction in complicated sternal wound infection after cardiac surgery. Journal of Cardiothoracic Surgery 2013 8(Suppl 1):P58. 